\title{
Estimation of predominant histological alterations in cholecystitis and cholelithiasis of human gallbladder an analytical and statistical study through the approach of routine histochemistry
}

\author{
Dr Jyoti Prakash Pani ${ }^{1}$, Mr Shubham Pandey ${ }^{2}$, Dr Sankarsan Pani ${ }^{3}$, Dr M N \\ Mahendrakar $^{3}$, Dr Karuna H. Katti ${ }^{4}$ \\ ${ }^{1.2}$ (Department of Anatomy, Institute of Medical Sciences Varanasi, UttarPradesh 221005/ Banaras Hindu \\ University, India, ) \\ 3,(Department of Surgery, M.G.M. Medical College, Kamothe, Kalamboli/M.G.M.University of Health and \\ Sciences Navi Mumbai, India) \\ ${ }^{3,4}$ (Department of Anatomy, M.G.M. Medical College, Kamothe, Kalamboli/M.G.M.University of Health and \\ Sciences Navi Mumbai, India)
}

\begin{abstract}
The purpose of the present study is to compare histological changes in the wall of human gallbladder in abnormal conditions like cholelithiasis \& cholecystitis and find out the predominant risk factors for the development of cholelithiasis from primary stage like cholecystitis. To conduct case control study, 60 normal (control group) human gallbladders \& 30 abnormal (case group) samples of human gallbladders having cholelithiasis and cholecystitis were obtained and processed \& 9 slides were obtained and stained by $H \& E$.. Different histological findings were noted in the various layers of gallbladders. Epithelial hyperplasia, dysplasia with erodification of mucosa and sub epithelial haemorrhages was denoted in both cholelithiasis \& cholecystitis. On the behalf of statistical evidence, the present study shows both group case and control are highly significant. Predominant histological alterations were estimated in percentage by counting the number of sign and symtoms or alterations observed in various layers of diseased human gall bladder like cholecystitis and cholelithiasis and the percentage was evaluated by correlating with the normal gallbladder histological representation either/or minimal recessive histological alterations in the normal one. Predominant histological alterations were estimated and found maximum epithelial break was $62.5 \%$ in cholelithiasis where as $59.09 \%$ in cholecystitis
\end{abstract}

Keywords: Epithelial hyperplasia, Haematoxylin and Eosin staining, Macrophage infiltration, Plasma cell infiltration, Rokitansky Aschoff Sinus.

\section{Introduction}

Gallbladder diseases like cholecystitis and cholelithiasis are very common particularly in fatty, fertile \& female of forty to fifty but equally affects male and children. ${ }^{[1]}$ Cholecystitis and cholelithiasis appear to be increasing in incidence over past couple of decades in India and western world due to increased intake of fatty and high calorie diet and increased consumption of alcohols. ${ }^{[2,3]}$ The nature of cholecystitis and cholelithiasis is, predominantly it seen in fatty, fertile female of forty to fifty. In these particular patients these diseases specifically represents with various sign and symptoms like severe pain in Murphy's point (+Ve Murphy's sign) in right upper quadrant of abdomen, Bilious vomiting, mild to moderate increase in temperature. These diseases produce mild to moderate yellow discolouration of cornea, nail beds in latent stage because of obstructive jaundice. There is also severe loss of appetite and loss of weight. Though cholecystitis is not so virulent but in later stage it produces virulent complications. Cholelithiasis is an acute condition it needs urgent cholecystectomy.

1.1. "Anatomy of normal gall bladder" The fossa for the gallbladder extends from the right end of the porta hepatis to the inferior border of the liver ${ }^{[4]} \mathrm{It}$ is 7 to $10 \mathrm{~cm}$ (3 to 4 inches) long. $3 \mathrm{~cm}$ broad at its widest part and about 30 to $50 \mathrm{ml}$ in capacity. ${ }^{[5]}$ It is divisible into fundus, body and neck. ${ }^{[6]}$ Neck is continues as cystic duct $\&$ is marked by a constriction. Histologically it shows 4 layer's and lacks muscularis mucosa. ${ }^{[7]}$ It shows inside out, mucosal layer, loose sub mucosa, muscle layer and adventitial (serosal) layer. In cholecystitis and cholelithiasis the wall of human gallbladder shows, certain histological changes. The present study is carried out to find out the same. ${ }^{[8-10]}$

1.2."Review of literature" Schwartz SI, Dale WA in 1958 studied primary sclerosing cholangitis and found 
coexistence of inflammatory lesions in the gall bladder, abundance of lymphocyte and plasma cells in the sub mucosa with those present in the bile duct. This is usually associated with cholecystitis in which abundance of lymphoid follicles \& moderate to severe chronic inflammatory cells were found. ${ }^{[11]}$ Thorpe MEC, Scheurer PJ, Sherlock S et al in 1967 studied primary sclerosing cholangitis in biliary tree \& ulcerative colitis and got the same finding as above. ${ }^{[12]}$

- Tami Yama H, Yamigiwa H in 1987 studied cholelithiasis \& found dysplasia carcinoma sequence histologically. ${ }^{[13]}$ Jeffery GP, Shilkin KB, Carrelo S et al in 1991 studied histological and immunohistochemical study of the gall bladder lesions in primary sclerosing cholangitis \& found abundance of lymphoid follicles \& plasma cells within sub mucosa. ${ }^{[14]} \&$ moderately to severe chronic inflammations were also found.Badke A, Bohm B, Schwenk W, Stock W et al in 1993 studied histological changes in cholelithiasis gall bladder \& found inflammatory changes in some \& fibrotic changes in others. ${ }^{[15]}$ Csendes A, , Maluenda F, Smok G, , Diaz JC, , Korn O, Burdiles P et al in 1998 studied histological findings of gallbladder mucosa in 95 control subjects and with asymptomatic gall stones. Their findings suggest that chronic inflammatory changes can occur in the gall bladder mucosa prior to appearance of macroscopic stones. ${ }^{[16]}$ Baylis High OB.Lipid in: Bancroft JD, Stevens A. et al in 1982 studied 70 cholecystitis gall bladders for lipids in their epithelium. ${ }^{[17]}$ Jeffery GP, Carrello S, Reed WD et al in 1991 studied histological and immunohistochemical study of the gall bladder lesions in primary sclerosing cholangitis \& found abundance of lymphoid follicles \& plasma cells within sub mucosa of cholecystits gallbladder. ${ }^{[18]}$

\section{II. "Aim and Objectives"}

2.1. "Aim" The aim of the present study is to find out and compare the histological alterations in the inner histological layers of luminal wall of human gallbladder in abnormal conditions like cholecystitis and cholelithiasis through approach of routine histochemistry.

2.2. "Objectives" 2.2.1 To find out the histological changes in the inner luminal wall of the human gallbladder in above diseases and to compare them statistically through routine histochemistry approach.

\subsubsection{To find out statistically significant among those histological alterations.}

2.2.3 To proof, definitely cholecystitis is the initial condition of cholelithiasis.

2.2.4 The purpose of the present study is to evaluate and discuss those findings and those estimations.

2.2.5. "Contribution of the paper" The concept made in my manuscript was actually a plot revived from the original article of Thorpe MEC, Scheuer PJ, Sherlock S. on Primary sclerosing cholangitis with biliary tree \& ulcerative colitis. gut. of 1967.The concept to work on histological changes on human gallbladder was proposed by my supervisor Dr Karuna H. Katti first by the way of applying routine immunohistochemistry method. She and myself dually planned to do routine histochemistry by using H\&E stain and had planned to prepare 9 slides from each, total 9 slides for each sample which includes the work of routine histochemistry and to estimate the histological ulterations statistically to proof cholecystitis is the primary stage towards cholelithiasis.Dr Karuna H. Katti, Dr M N Mahendrakar, Dr G N Geetha collaboratively planned and advised me to procure samples from Dept. of Pathology M.G.M. Medical College and provide me a issue letter.The concept of this manuscript work was to observe histological changes in the wall of human gallbladder after stone formation and what are the histological alteration..Dr Charushila Shindhe was appointed as invigilator by my supervisor and my reviewer to cheque daily work done by me and to report them for smooth conduction of the manuscript work which is planned and described in the article.Mrs Padmashree Choughule was appointed as the Senior Lab.Technician to assist and to help me for smooth conduction of the immunohistochemistry work. I took the help of Dept. of Biochemistry, Dept. of Microbiology\& Dept. of Biotechnology for preparation of special stain and to maintain the $\mathrm{Ph}$. of the special stain.So according to my view all my supervisor,reviewer and my reporter including lab. technician had played a tremendous job in order to make the manuscript work successful.I wish them all the best for future.In my view they all have really played the role of guarantor who take all the responsibility to make the project successful.My Supervisor had given me the idea to collect the article.I solely searched all the review of literature, Me and Dr Charushila Shindhe had arranged those review of literature and references in chronological year wise and in alphabetical form.References are arranged in Vancouver system of referencing by me.Finally I had made a decision to publish this manuscript work.

\section{III. "Material \& Methods}

To conduct case control study, 60 normal (control group) human gall bladders and 30 abnormal (case group) samples of human gall bladders having cholelithiasis and cholecystitis were obtained from Department of Pathology M.G.M. Medical College, Navi- Mumbai (India). There were 22 samples of cholelithiasis (Chronic calculus cholecystitis) and 8 samples were of cholecystitis out of which 6 samples were of chronic 
cholecystitis and 2 samples were of chronic follicular cholecystitis. 44 normal gall bladder samples were selected in contrast to 22 cholelithiasis gall bladder samples and rest of the 16 normal were selected in contrast to 8 cholecystitis gall bladder samples.

The tissues were labelled and subjected to histological processing. ${ }^{[19]}$ From each sample 9 slides were taken, out of which -9 slides were stained by haematoxylin \& eosin stain (Routine histochemistry method). Estimation for the predominant histological alterations in various layers of gallbladder was done statistically to show difference of percentage between cholecystitis and cholelithiasis. The estimation was compared between specific histological layers of cholecystitis and cholelithiasis gall bladder.

\section{IV. "Results"}

Different histological findings were noted in the various layers of cholelithiasis \& cholecystitis gall bladder which were compared with the each other. In cholelithiasis samples the H\&E slides showed minimum and maximum break in continuity of epithelium in supranuclear part. No goblet cells were found. The honey comb shape epithelial distortion noted. The sub-epithelial haemorrhages noted. The epithelial dysplasia, hyperplasia and intactness also noted. The extensive damage of this layer was observed. Mucosa showed erosion and ramification. Maximum to minimum lymphocyte infiltration and lymphoid tissue proliferation were noted in successive layers. Cholelithiasis samples also showed the following changes in muscular layer, Normal pattern of epithelium were disturbed, multiple blood vessels with haemorrhages were found, the maximum infiltration lymphocytes and macrophages were noted. The extensive degeneration of villi, the lymphoid tissue and plasma cell proliferation were noted. Rokitansky Aschoff sinuses were found which were seen to be invaginated from muscular layer to perimuscular layer. Serosa showed same finding as perimuscular layer with addition to minimum infiltration of lymphocytes and sub-serosal haemorrhages. An estimation for the predominant histological alterations in various layers of gallbladder was done statistically in percentage between cholecystitis and cholelithiasis. Estimation was particularly confined to compare between each specific layer of cholecystitis and cholelithiasis human gallbladders. Percentage was evaluated by counting number of sign and symtoms from each sample correlating to the normal one and the result was subject for statistical analysis by histogram method. After staining nuclei were found blue \& cytoplasm were found pink in H\&E stain Staining with Sudan Black B simple lipid appeared bright red \& compound of other lipids appeared less strongly stained or unstained. ${ }^{[19]}$ Predominant alterations of epithelium of the cholelithiasis and cholecystits gallbladder were estimated and found maximum epithelial break was $62.5 \%$ in cholelithiasis where as $59.09 \%$ in cholecystitis. Minimum epithelial break was $50 \%$ in cholelithiasis where as $36.36 \%$ in cholecystitis. $0 \%$ goblet cell was found in epithelium in cholelithiasis where as $4.54 \%$ of goblet cell was found in epithelium in cholecystitis. Goblet is absolutely not seen in cholelithiasis where as $9.1 \%$ goblet cell seen in cholecystitis in epithelium. Lymphoid proliferation was estimated $12.5 \%$ in cholelithiasis where as $0 \%$ in cholecystitis. Epithial dysplasia estimated

$100 \%$ in cholelithiasis where as $36.36 \%$ epithelial dysplasia and intactness was estimated in cholecystitis.

\section{1. "changes seen epithelium in cholelithiasis "Fig.1"}

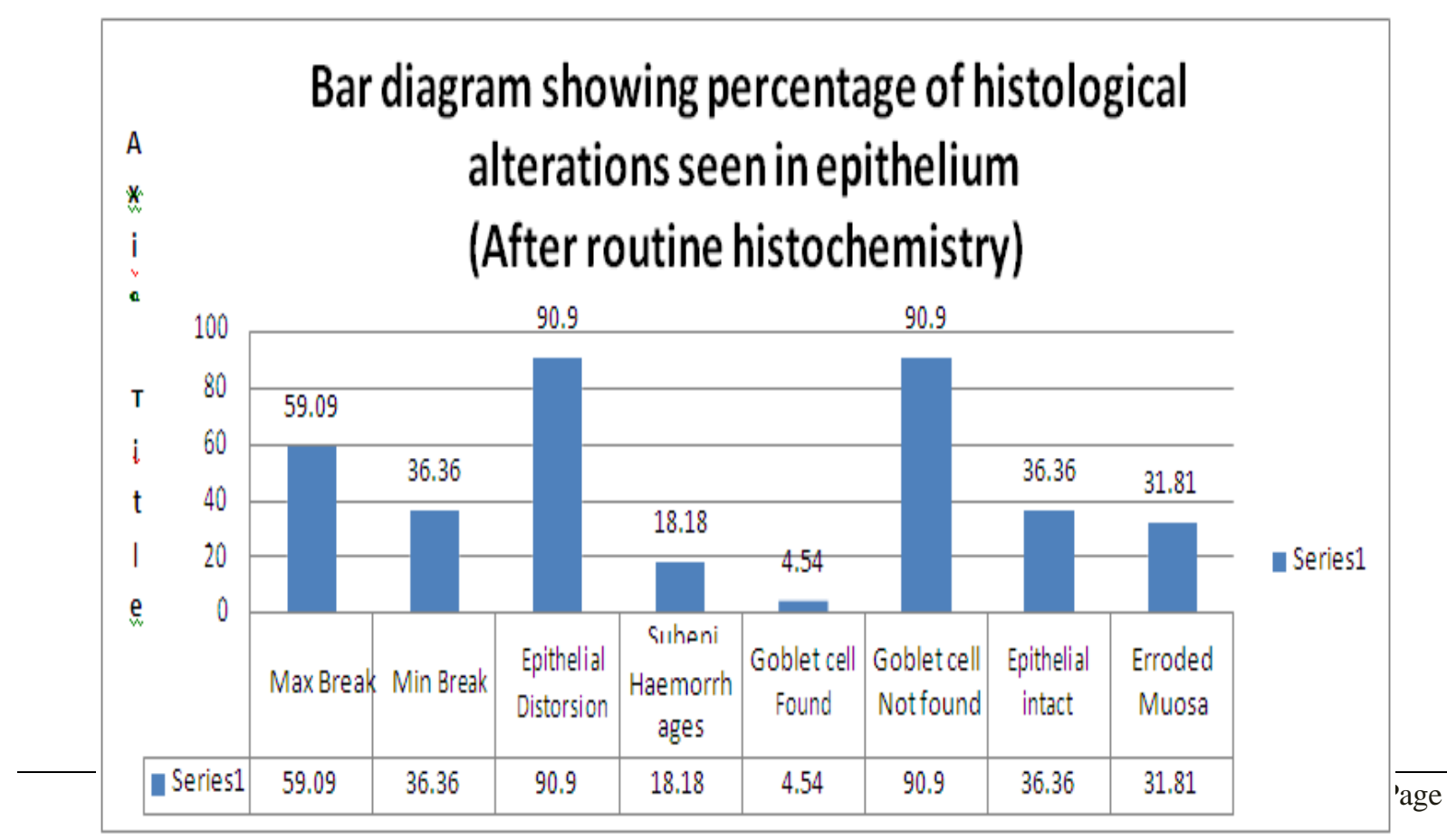




\section{1. "changes seen epithelium in cholelithiasis "Fig.1"}

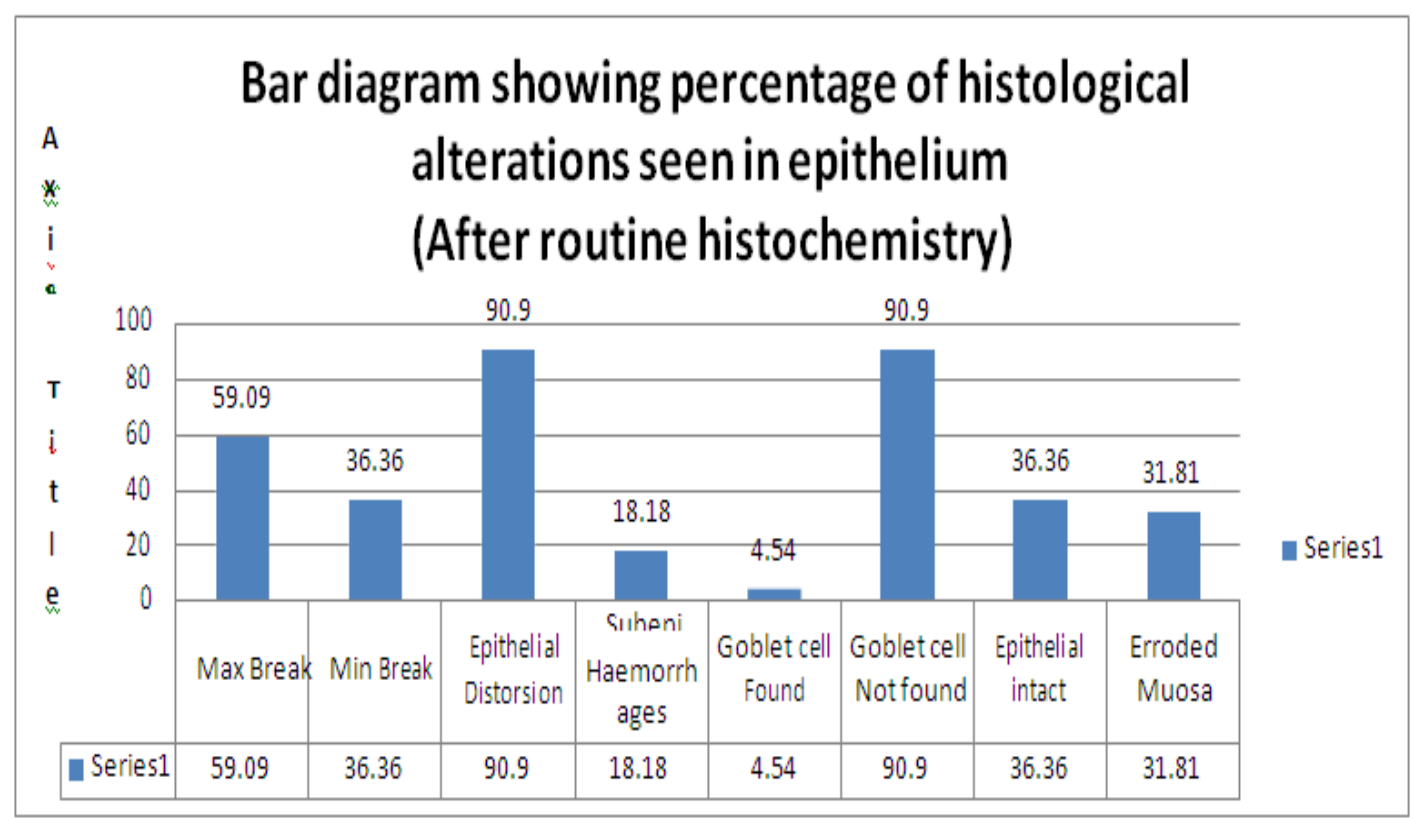

\section{2. "changes seen in epithelium in cholecystitis "Fig.2"}

Predominant alterations of lamina propria of the cholelithiasis and cholecystitis gallbladder were estimated and found area where maximum infiltration of lymphocytes were seen was $100 \%$ in cholelithiasis whereas same estimated value was observed in cholecystitis. Irregularity and gap between former layer was estimated 100\% in cholelithiasis where as cholecystitis gallbladder showed $90.09 \%$ estimated value.75\% eroded mucosa was estimated in cholelithiasis where as $0 \%$ was estimated in cholecystitis gall bladder. Value of total thickness of lamina propria was estimated in percentage and was found $12.5 \%$ in cholelithiasis whereas cholecystitis showed $9.09 \%$. Percentage of macrophages and plasma cells was estimated and was found $86.36 \%$ and $68.18 \%$ in cholelithiasis gallbladders and was estimated $0 \%$ in cholecystitis whereas $0 \%$ in cholecystitis.

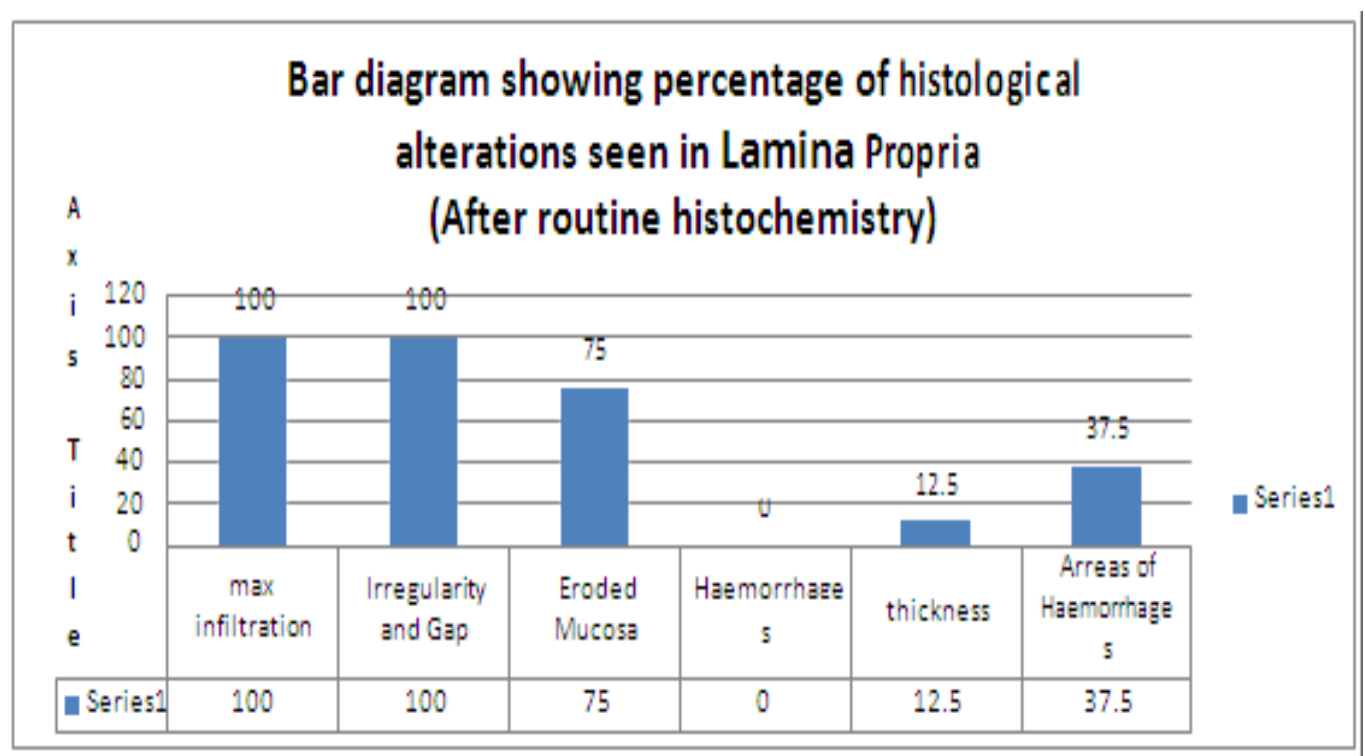




\section{3. "changes seen in lamina propria in cholelithiasis "Fig.3"}

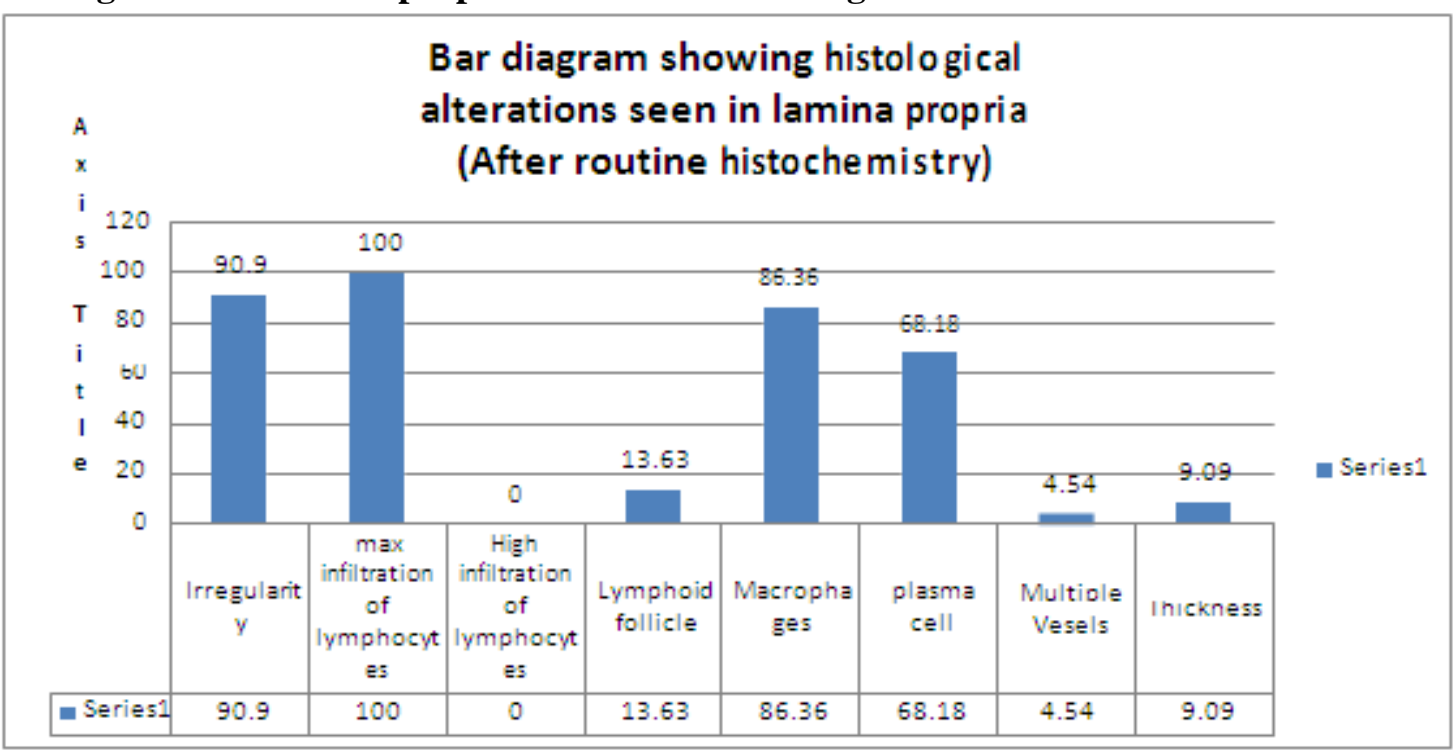

\section{4. "changes seen lamina propria in cholecystitis "Fig.4"}

Predominant alterations of muscular layer of the cholelithiasis and cholecystitis gallbladder were estimated and found $100 \%$ irregularity in cholelithiasis whereas $63.63 \%$ estimated value was observed in cholecystitis. Gap between former layers was estimated $100 \%$ in cholelithiasis where as cholecystitis gallbladder showed 54.54\% estimated value.50\% Rokitansky Aschoff sinus was estimated $50 \%$ in cholelithiasis gall bladder where as estimated $40.9 \%$ was estimated in cholecystitis gall bladder. Maximum infiltration of lymphocyte was estimated $100 \%$ in cholelithiasis whereas cholecystitis gall bladder showed $45.45 \%$. Percentage of macrophages and plasma cells was estimated $100 \%$ in cholelithiasis gallbladders and was estimated $27.27 \%$ in cholecystitis gall bladder. Villi estimated $87.5 \%$ in cholelithiasis gall bladder where as estimated $31.81 \%$ in cholecystitis gall bladder. Apart from above analysis cholecystitis gall bladder showed $13.63 \%$ medium infiltration of lymphocytes and $59.09 \%$ of multiple haemorrhages in this layer.

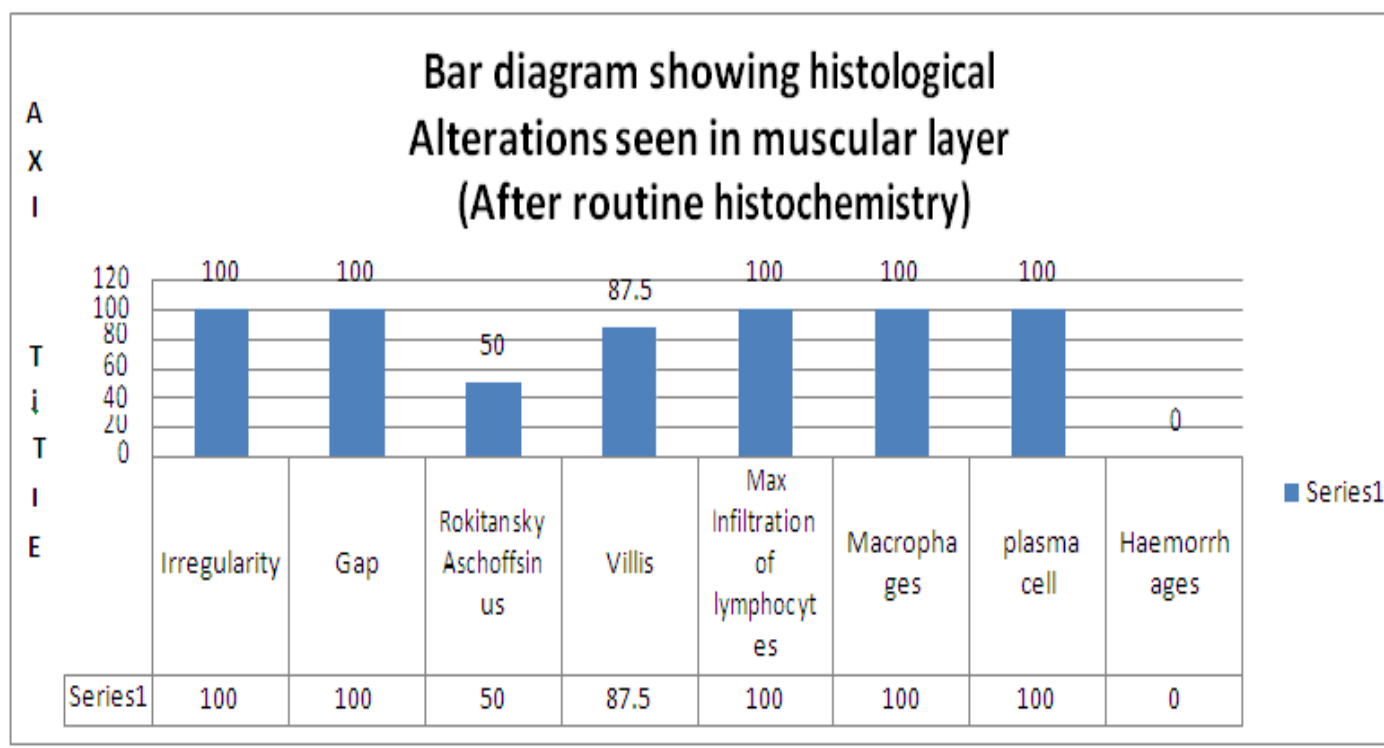




\section{5."changes seen in muscular layer in cholelithiasis "Fig.5"}

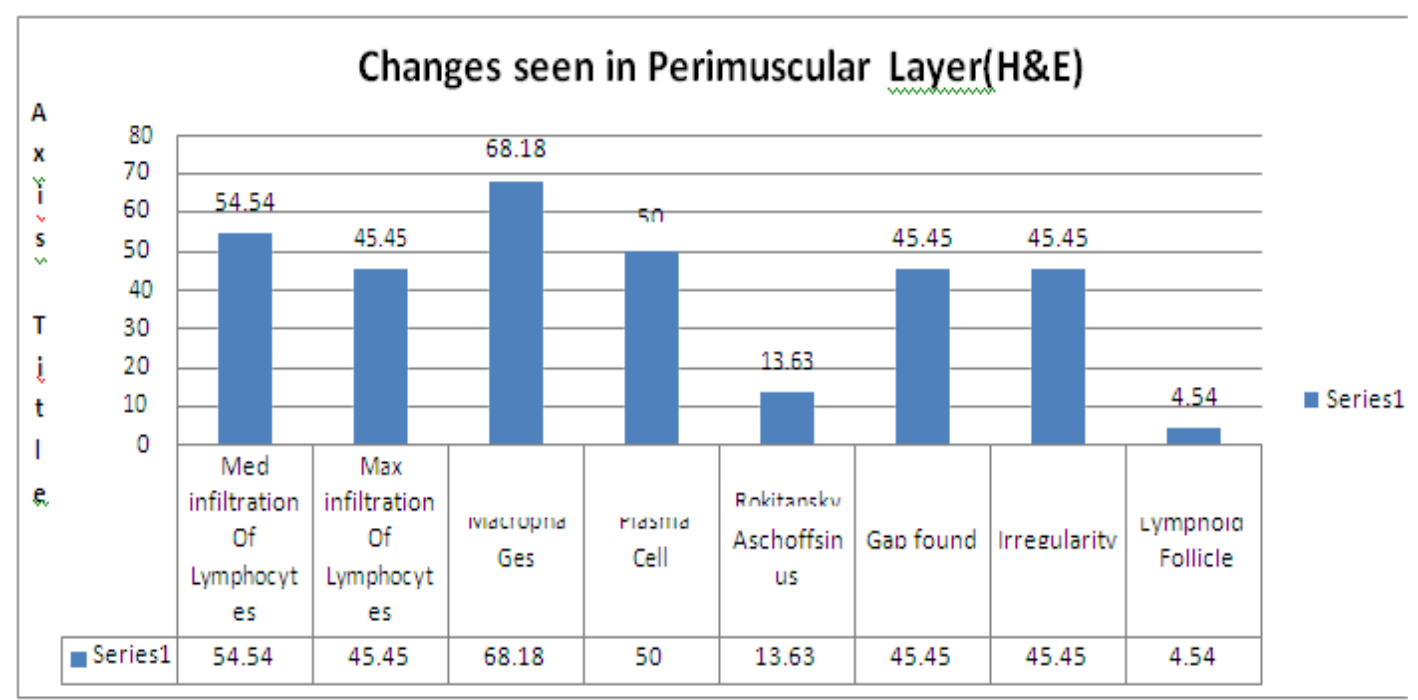

4.6. "changes seen in muscular layer in cholecystitis "Fig.6"

Predominant histological alterations of perimuscular layer of the cholelithiasis and cholecystitis gallbladder were estimated and found $100 \%$ medium infiltration of lymphocytes in cholelithiasis whereas $54.54 \%$ estimated value was observed in cholecystitis. Macrophage and plasma cell infiltration was estimated $100 \%$ each in cholelithiasis where as cholecystitis gallbladder showed $68.18 \%$ \& $50 \%$ estimated value. Gap found with former layer was estimated $87.5 \%$ in cholelithiasis whereas $45.45 \%$ estimated value was observed in cholecystitis.Apart from this $45.45 \%$ irregularity is observed in cholecystitis, $13.63 \%$ Rokitansky Aschoff sinuses is estimated in this particular layer.

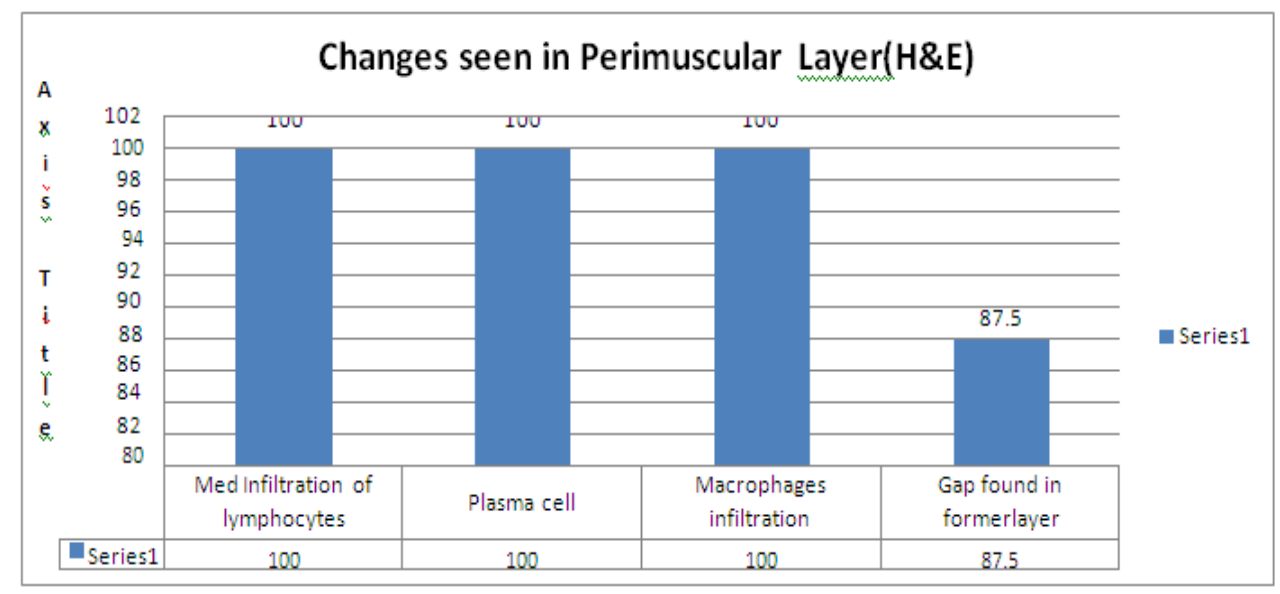

4.7. "changes seen in perimuscular layer in cholelithiasis "Fig.7"

\section{8. "changes seen in perimuscular layer in cholecystits "Fig.8"}

Predominant alterations of serosal layer of the cholelithiasis and cholecystitis gallbladder were estimated and found $100 \%$ minimum infiltration of lymphocytes in cholelithiasis whereas $95.45 \%$ estimated value was observed in cholecystitis.Subserosal haemorrhages was estimated $75 \%$ in cholelithiasis whereas estimated $8.18 \%$ in cholecystitis in this particular layer. 


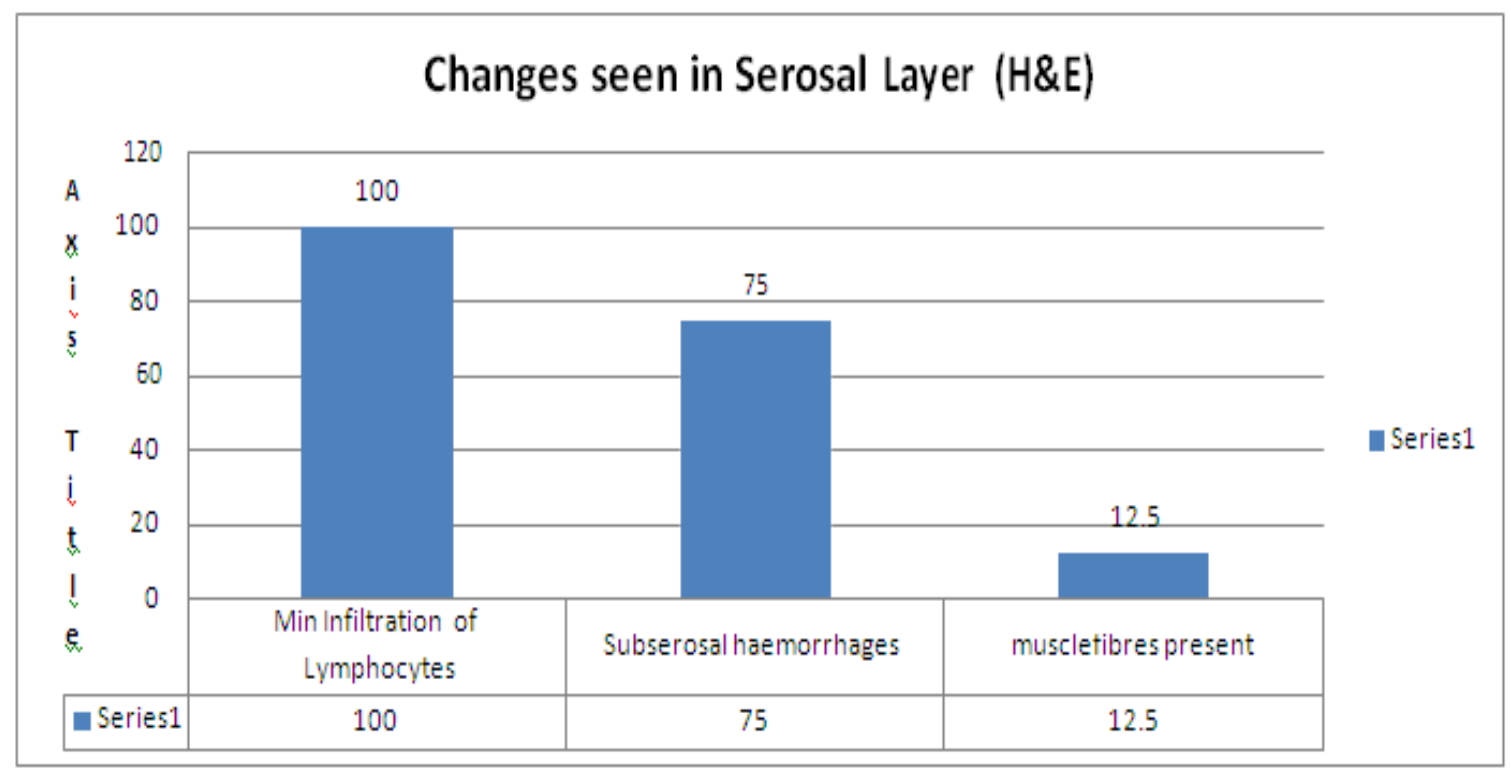

4.9.“changes seen in serosal layer in cholelithiasis "Fig.9"

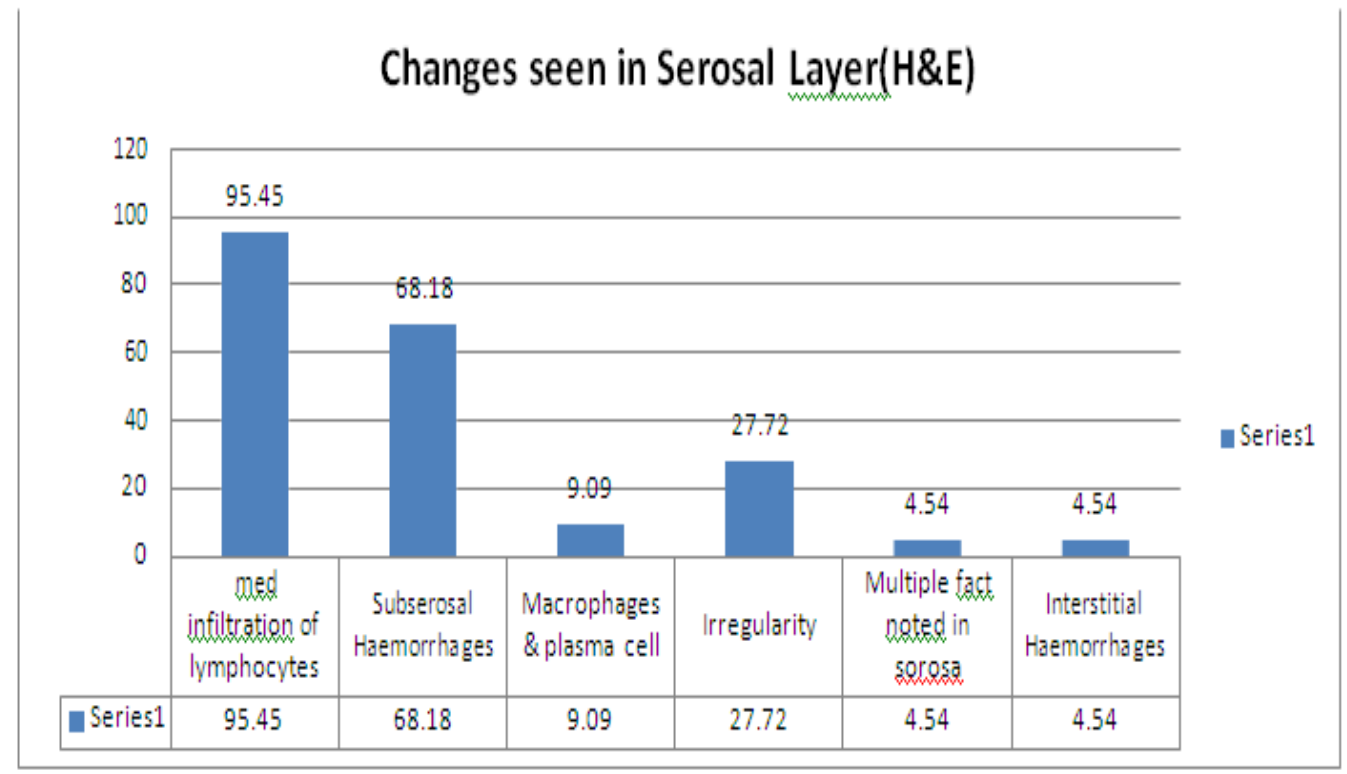

4.9.1."changes seen in serosal layer in cholecystits "Fig.10"

V. "Discussion"

In this present study 8 cholecystitis and 22 cholelithiasis gall bladders were studied histochemically by H\&E stain (For routine histochemistry)

The epithelial hyperplasia, dysplasia and/or epithelial distortion with erosion of mucosa in both cholecystitis and cholelithiasis. ${ }^{[3]}$.

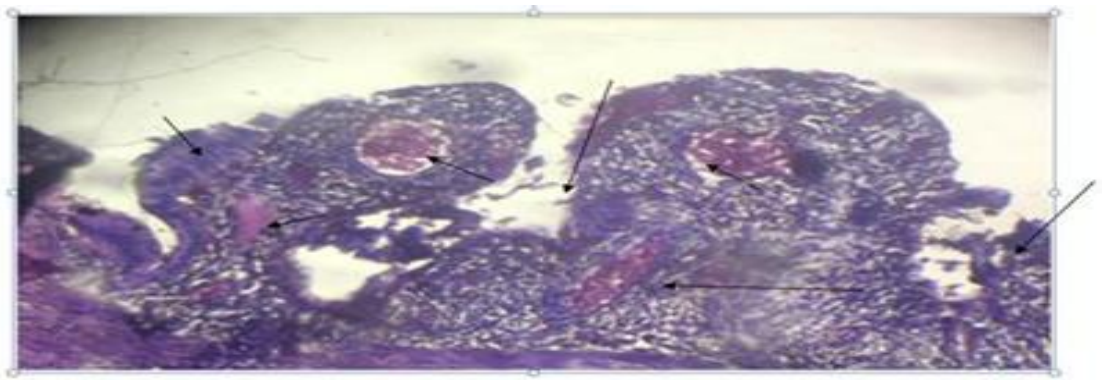




\section{1.lymphocytic infiltration and epithelial dysplasia "Fig.11"}

In many cases it was associated with sub epithelial haemorrhages ${ }^{[12]}$.

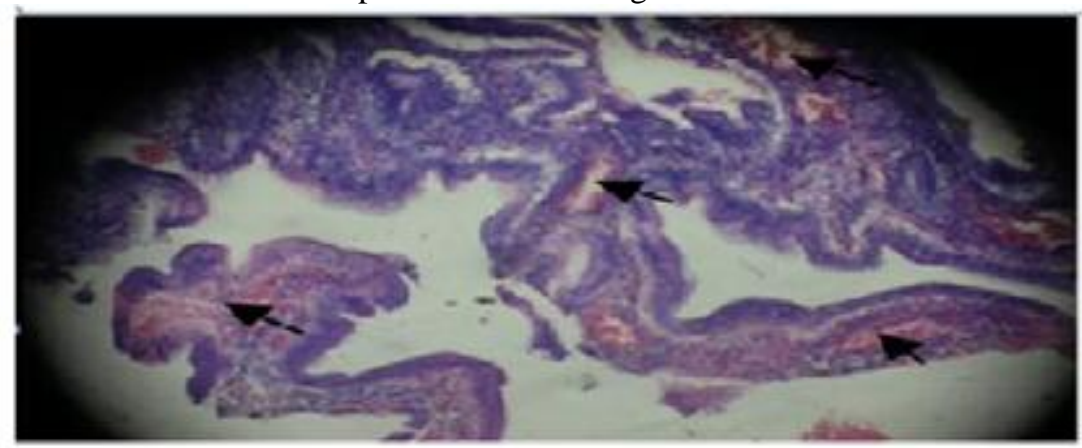

\section{2.subepithelial haemorrhages "Fig. 2 "}

In few cases they were even extending up to deep layers. Accumulated epithelial lipids were seen. Goblet cells were absent. The infiltrate was seen mainly in sub mucosa ${ }^{[13]}$ (Fig.11) (Fig.12).It extends up to muscular layer in few cases. It was focal and patchy in nature with presence of abundant lymphocytes and plasma cells ${ }^{[14]}$ (Fig.11). Multifocal dysplasia was seen ${ }^{[12]}$ (Fig.11). Rokitansky Aschoff sinuses were seen in muscular layer.

These were irregular gland like mucosal pockets extending deep into the thickened muscle layer ${ }^{[15,20]}$.

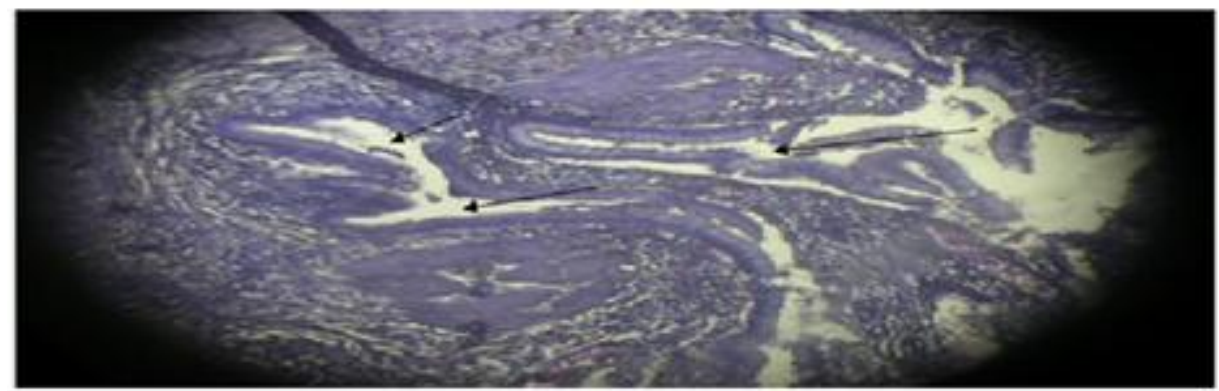

\section{3.rokitansky aschoff sinus"Fig,3"}

It is observed that $80 \%$ cholelithiasis is due to infection by bacteria. The centre of each gallstone has some bacteria and epithelial cells. It is said that gall stone is a tomb stone erected in the memory of the bacteria embedded in it. Most of the cholelithiasis is due to infection.

\section{VI. "Conclusion"}

In the present study an attempt is made to demonstrate and estimate the histological alterations in cholecystitis and cholelithiasis gall bladders by histogram analysis and to compare it with normal one. The main purpose of this study is to estimate predominant alteration in specific layer of diseased

gallbladder and to compare it with other each other and the normal one which shows no histological alteration or minimal recessive alterations. A conclusion is made out from this above data is that; cholecystitis is the primary stage of stone formation prior to secondary stage like cholelithiasis. Once these alterations occur, they alter the normal tissue pattern \& can induce carcinogenic progression \& metastasis. The advantages of this work are early differential diagnosis between the two and to give effective treatment as earlier as possible in order to prevent stone formation which ultimately leads towards carcinoma gall bladder. Prevention is better than cure. Prevent sulfation and sailylation. The limitation of this present work is further study still not done yet to discover effective drug which will be able to prevent sulfation and sailylation. It needs a further therapeutic research. The possible application of this present work is in clinical field for early detection and differential diagnosis. The importance is early differential diagnosis between the two through the approach of routine histochemistry and statistics when this type of work involves a large population. This type of work can be extended throughout world.

\section{"Acknowledgement"}

I acknowledge all my co-authors and my reviewers for my study and wish them all the best for the future. 


\section{References}

[1]. H. Mohan, Extra Hepatic Biliary Apparatus-Gall bladder (Text Book of Pathology. Chapter 19 5th Edition 2005):658-664.

[2]. M.C. Carey Pathogenesis of gall stone. Am J. Surg. 1993,165:410-410.

[3]. S. Sherlock, Diseases of the liver and biliary system (Blackwell Scientific Publication, Oxford. 1997) 10th Edition:1-714.

[4]. J.E. Dussek, L.H. Bannister, M.M.Barry et al Gray's Anatomy IN: Nervous system. Chapter12, Churchill Livingston Edinburgh. 2010,38 ${ }^{\text {th }}$ Edition:1795-1812, 140,141,1810-1812,144,151-60.

[5]. F.G. Fleischner, V. Sayegh, Assessment of the size of the liver, Roentgenologic consideration. (New England Journal of Medicine. 1958) Med 259:271-274.

[6]. $\quad$ J. Meilstrup Imaging atlas of normal gall bladder and its variants. CRC Press (an imprint of Taylor \& Francis group) Boca Raton FL].pp.4.ISBN/0-8493-4788-2.

[7]. S.H. Difiore, Mariano., Chapter: 7. The digestive system, the accessory digestive organs Gallbladder. (Organ's section Atlas of istology. 2009), $\left(7^{\text {th }}\right.$ Edition):204-205.

[8]. I.B. Singh, Chapter-16. Extra hepatic biliary apparatus Gall bladder (Text book of human histology with colour atlas, 2006), $5^{\text {th }}$ Edition:259-260

[9]. A.J. Chiardo, G.B. Chapman, K. Weineke et al. The fine structure of mucosal epithelial cell of a pathological human gallbladder. Anat Rec, 1966,12.155:579-616.

[10]. $\quad$ ^"Slide5:GallBladder”JaydochistoWeb.University

Kankas.http://www.kumc.edu/instruction/medicine/anatomy/histoweb/epithel/epith05.htm.Retrieval of on. 2007:06-29.

[11]. S.I. Schwartz, W.A. Dale Primary Sclerosing Cholangitis: A review and report of six cases. Arch Surg. 1958,77:350-439.

[12]. M.E.C. Thorpe, P.J. Scheuer, S. Sherlock et al Primary sclerosing cholangitis with biliary tree \& ulcerative colitis. gut. 1967,8:435-448.

[13]. H. Tami Yama, H. Yamigiwa Intestinal metaplasia - Dysplasia carcinoma sequence of the gallbladder. Acta Pathol. JPN. 1987,36:989-997.

[14]. G.P. Jeffrey, K.B. Shilkin, S. Carrello et al Histological and immunohistochemical study of the gallbladder lesion in primary sclerosing cholangitis. gut. 1991,32:424-429.

[15]. A. Badke, B. Böhm, W. Schwenk et al Histopathological changes of gall bladder and liver parenchyma in symptomatic cholelithiasis. Dtsch med Wschr. 1993,118;:Issue:22,Jun4:809-813.

[16]. A. Csendes, F. Maluenda, G. Smok et al Histological findings of gall bladder mucosa in 95 control subjects and 80 patients with asymptomatic gall stones. Journal of Digestive diseases and sciences. 1998,43:931-934

[17]. 17) A. Stevens, J.D. Bancroft, O.B. Baylis High Lipid in:, et al Ch12, Theory and practice of Histological Technique. Churchill living stone, Edinburgh. 1982,2 $2^{\text {nd }}$ Edition:217-241.

[18]. G.P. Jeffery, S. Carrello, W.D. Reed et al Histological and immunohistochemical study of the gallbladder lesion in primary sclerosing cholangitis. gut. 1991,32:424-429.

[19]. E.A. Wallington, R.A.B. Drury, Method to prepare Combined PAS-AB stain and Sudan Black B stain. (Carlton's Histological techniques.) $5^{\text {th }}$ edition Chapter: $3,4,7,13,15: 36-56,57-75,125-150,232-259,285-297$.

[20]. J. Ludwig Surgical Pathology of the syndrome of primary sclerosing cholangitis. Am J Surg Pathol. 1989,9:43-49. 